\title{
Siderophore Producer Pantoea Brenneri AS3 as a Fungicidal
}

\section{Agent}

\section{Itkina DL*, Suleimanova AD and Sharipova MR \\ Institute of Fundamental Medicine and Biology, Kazan Federal University, Russia}

*Corresponding author: Daria Leonidovna Itkina, Kazan Federal University, Institute of Fundamental Medicine and Biology, 420008, Kazan, Kremlyovskaya Street, 18, Russia, Tel: 89503133963; Email: Laia9301@mail.ru

\section{Mini Review \\ Volume 4 Issue 3}

Received Date: November 30, 2019

Published Date: December 10, 2019

DOI: $10.23880 /$ oajmb-16000153

\section{Abstract}

With the growth of the planet's population and the depletion of mineral resources, the increase in crop yields, the search for environmentally friendly technologies, the use of enzymes and siderophores of bacterial origin, or the use of bacterial strains that promote plant growth (PGP) are becoming more urgent. Was found in a strain of bacteria Pantoea brenneri AS3 produced of siderophore $(82.05 \mu \mathrm{M})$ accounted for 28 hour culture. The strain Pantoea brenneri AS3 demonstrate antagonistic activity against all studied phytopathogenic fungi. Antagonistic activity was measured on the basis of growth inhibition of micromycetes colony compared to the control plates. The highest antagonistic activities of both strains were observed against F. solani (87\%).

Keywords: Bacteria; Pantoea; Siderophores; Antagonistic activity

Abbreviations: PGPR: Plant Growth Promoting Rhizobacteria; PGP: Promote Plant Growth; IAA: Indole-3Acetic Acid.

\section{Introduction}

Fighting against plant diseases caused by harmful microorganisms and increases the quality and productivity of economically important crops is an urgent problem of global agriculture. The national economy is experiencing a huge annual economic loss due to the development of fungal infections of grain and solanaceous crops [1]. Plant pathogenic fungi cause loss of major food crops of the world, namely barley, rye, durum wheat, maize, rice, potato, tomato.

The intensive use of chemical fertilizers and pesticides in agriculture ensures high productivity and quality, but this approach is expensive and creates risks to the environment and human health [2]. Because of the undesirable features of these substances in recent years a growing interest in environmentally friendly biological preparations. Different bacterial genera are vital components of soils. They are involved in various biotic activities of the soil ecosystem to make it dynamic for nutrient turn over and sustainable for crop production [3]. They stimulate plant growth through mobilizing nutrients in soils, producing numerous plant growth regulators, protecting plants from phytopathogens by controlling or inhibiting them; improving soil structure and bioremediating the polluted soils by sequestering toxic heavy metal species and degrading xenobiotic compounds (like pesticides).

Bacteria are the most abundant microorganisms within soil, and those that have a beneficial effect on plant growth or health are commonly referred to as plant growth promoting rhizobacteria (PGPR) [4]. The mechanisms by which PGPR can act beneficially on plant 


\section{Open Access Journal of Microbiology \& Biotechnology}

growth have not been fully elucidated, but proposed mechanisms include production of plant growth regulators such as indole-3-acetic acid (IAA), asymbiotic nitrogen fixation, solubilization of soil phosphorus compounds and other nutrients, and antagonism against plant pathogens through the excretion of siderophores, cellulose, protease, antibiotics and cyanide [5]. The range of useful properties of soil microorganisms is of interest to search for new strains that may be used as biopesticides and biofertilizer in agriculture.

Thus, the aim of the work was to study and characterization of antagonistic properties of Pantoea brenneri AS3.

\section{Material and Methods}

We used bacterial strain is Pantoea brenneri AS3, isolated from samples soil of the Republic of Tatarstan and identified by molecular genetic analysis methods. Bacteria were grown in medium LB [6] (G/l dH20): Tryptone - 10; yeast extract - 5; $\mathrm{NaCl}$ - 5; agar - 2; pH 8.5

Following phytopathogenic fungi were used in these experiments: Alternaria alternate - Isolated from infected roots of lettuce and parsley. Fusarium solani isolate TVD_Fungal-Culture126; Fusarium tricinctum strain Z5; Fusarium oxysporum strain CEF-06; Fusarium avenaceum strain 1; Fusarium sp 1.5 isolated from infected potato tubers. Identification of the micromycetes conducted on morphological characteristics and by molecular genetic analysis methods.

The fungi were cultivated in the Czapek medium $\left(\mathrm{NaNO}_{3}, 3.0 \mathrm{~g} ; \mathrm{K}_{2} \mathrm{HPO}_{4}, 1.0 \mathrm{~g} ; \mathrm{MgSO}_{4} \times 7 \mathrm{H}_{2} \mathrm{O}, 0.5 \mathrm{~g} ; \mathrm{KCl}, 0.5\right.$ g; $\mathrm{FeSO}_{4} \times 7 \mathrm{H}_{2} \mathrm{O}, 0.01 \mathrm{~g}$; agar, $15 \mathrm{~g}$; distilled water, $900 \mathrm{ml}$; $\mathrm{pH}$ 4.5) [7]. The plates were incubated at $28^{\circ} \mathrm{C}$ for $5-14$ days. Cultivation of bacteria was carried out in $100 \mathrm{ml}$ flasks at a volume ratio of medium volume to the volume of the flask 1: 5 on a laboratory shaker intensity $200 \mathrm{rev} /$ min at a temperature of $37^{\circ} \mathrm{C}$ rocking. Seed served 12 hour inoculum. Characteristics of the biochemical properties of the strain P. brenneri AS3 production siderophores and antifungal metabolites.

Siderophore production was assessed on chrome azurol S (CAS) agar plates by observing the color change from blue to colorless. The plates were incubated at $30^{\circ} \mathrm{C}$ for 5-7 days [8]. Seeding was carried out in duplicate with $5 \mathrm{ml}$ of cell suspension, washed M9 minimal medium, previously grown on a rich medium LB. M9 media [9]. (G / l dH2O): $\mathrm{Na} 2 \mathrm{HPO} 4 * 12 \mathrm{H} 2 \mathrm{O}-16.82 ; \mathrm{KH} 2 \mathrm{PO} 4$ - 3; NaCl $0.5 ; \mathrm{NH} 4 \mathrm{Cl}-1 ; \mathrm{pH}$ 7.4. On medium, in addition after autoclaving made sterile micronutrients, $1 \mathrm{M} \mathrm{MgSO}{ }^{*}$ $7 \mathrm{H} 2 \mathrm{O}$ - $2 \mathrm{ml} ; 1 \mathrm{M} \mathrm{CaCl} 2$ - $0.1 \mathrm{ml} ; 20 \%$ Glucose - $10 \mathrm{ml}$. We used as a control strain Salmonella typhimurium, which forms siderophores. The density of the test and control cells of the strain was OD600 $=0.1$.

The ability to form a line of catechol siderophores studied on M9 minimal salt medium in a volume of $20 \mathrm{ml}$ with the addition of bipyridyl (3.36 L) at Arnow method. Sowing was carried out on medium, making the cell suspension Pantoea brenneri AS3 strain washed M9 medium until OD600 $=0.1$. The culture was incubated for 72 hours at $37^{\circ} \mathrm{C}$ with shaking $200 \mathrm{rpm} / \mathrm{min}$. As a control, an M9 medium supplemented with $5 \mathrm{~m} \mathrm{FeSO4,}$ sowing was conducted in the same manner as in the experiment. Catechol siderophore concentration measurement series were carried out as follows: every hour in aliquots of $400 \mathrm{ul}$ and was centrifuged at $13 \mathrm{k} /$ min for 2 minutes, then a 96-well plate were added $50 \mathrm{ul}$ of the supernatant; was added $50 \mathrm{ul} 0.5 \mathrm{M} \mathrm{HCl}$, and the mixture $50 \mathrm{mkl} \mathrm{NaMoO} 4 \mathrm{NaNO} 2$ and 50 mu.l of $1 \mathrm{M} \mathrm{NaOH}$. Absorption measurements were performed on a spectrophotometer at a wavelength of $490 \mathrm{~nm}$.

A calibration curve is constructed by 2,3dihydroxybenzoic acid (2,3-DHBA) from 0 to $1000 \mathrm{mM}$ in increments of $25 \mathrm{~mm}$. According to the formula of the calibration curve $y=0.0019 x+0.0401$ we found the amount of siderophore produced. Theoretical value of biomass is determined by the formula: $M=(A-B) 1000 /$ $\mathrm{V}$, where M - dry biomass $\mathrm{g} / \mathrm{l}$; A mass of cells with Eppendorf; B - mass of the empty Eppendorf; V - volume of QOL taken for centrifugation ml. The actual measured cell biomass after centrifugation by drying in a vacuum evaporator firm Labconco FreeZone 2.5.

\section{In Vitro Antagonistic Activity Assay}

The interaction of Pantoea brenneri AS3 with pathogenic fungi was performed using the in vitro dualculture analysis. The $8 \mathrm{~mm}$ diameter mycelial disc was cut from the target fungi colony that had been cultured on Czapek plates for seven days was placed on fresh Czapek plate. Test bacterial strains grown on LB plates for $48 \mathrm{~h}$ were cut with a sterile scalpel $(8 \mathrm{~mm})$. Bacterial blocks were placed at the distance of $3 \mathrm{~cm}$ from the fungal block on the same agar plate. Control plates without bacterial strains were prepared simultaneously. The plates were incubated at $28^{\circ} \mathrm{C}$ for $7-14$ days and examined for the inhibition zones of fungal growth. To calculate the percent of inhibition we repeated these experiments for three times. The growth inhibition of the test fungus was calculated using this formula: 


\section{Open Access Journal of Microbiology \& Biotechnology}

where

$$
\text { Inhibition }(\%)=[(\mathrm{R}-\mathrm{r}) / \mathrm{R} \times 100]
$$

R- (A control value) represents the radial growth of fungus in control sets.

$r$ - The radial growth of the fungus in sets with bacteria.

\section{Results and Discussion}

Strain Pantoea brenneri AS3 was isolated from the forest soil Republic of Tatarstan, Russia. The isolate was characterized as Gram-negative, motile and rod-shaped bacterium $0.5 \mu \mathrm{m}$ to $1.5 \mu \mathrm{m}$ length. Colonies were round, smooth and shiny after incubation at $37^{\circ} \mathrm{C}$ for $24 \mathrm{~h}$. Longer incubation (2-3 days) of the isolate resulted in production of yellow pigment.

The strain Pantoea brenneri AS3 demonstrate antagonistic activity against all studied phytopathogenic fungi. Antagonistic activity was measured on the basis of growth inhibition of micromycetes colony compared to the control plates. The highest antagonistic activities of both strains were observed against F. solani (87\%). A high degree of growth inhibition (from $58 \%$ to $87 \%$ ) of the bacterial strain discovered in relation to all the investigated representatives of the genus Fusarium, genus and Alternaria alternate (71\%). Minimum ability to inhibit fungal growth was observed in relation to the genus Bipolyaris sorokiniana - 33\%. Thus, it was found that the strain Pantoea brenneri AS3 during growth forms compounds having fungicidal activity towards micromycetes genera Fusarium, Alternaria and Bipolyaris. The presence of the fungicidal activity of the strain P. vagans can serve as a basis for the creation of new microbial Agri to address the problems associated with plant diseases caused by members of the genus Fusarium, Alternaria and Bipolyaris (Figure 1).

Iron is an important nutrient for all life forms, but in the soil it is in the insoluble trivalent form (Fe3+). Siderophores are low molecular weight redox active substances that reduce $\mathrm{Fe} 3+$ to $\mathrm{Fe} 2+$ and are produced by various microorganisms in the soil. Microorganisms produce siderophores for their own purposes and indirectly act as biocontrol agents since they lead to competitive iron deficiency in phytopathogenic organisms.

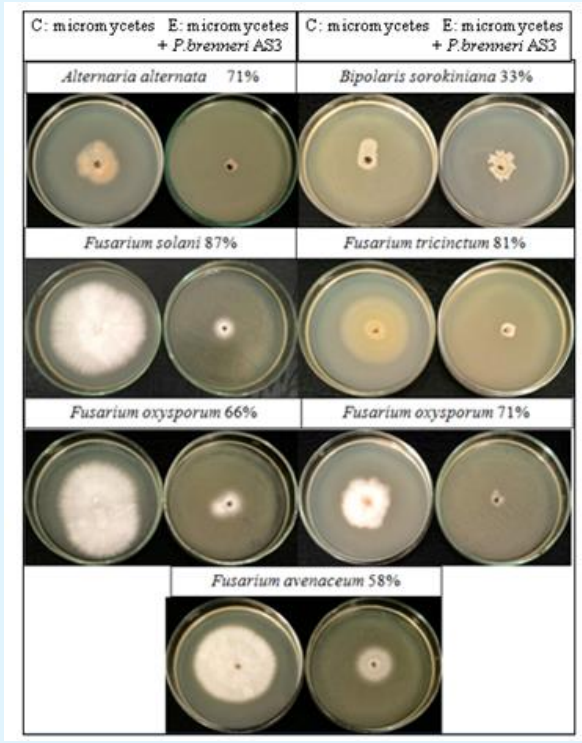

Figure 1: antagonistic effect produced. On the left, a medium with micromycetes without bacterial growth of $\mathrm{P}$. brenneri AS3 was used as a negative control (C); right experience (E).

The ability to form a strain of P. brenneri AS3 siderophores were detected on the differential medium CAS - agar chromazurol S. Formation of enlightenment zone $(0.7 \mathrm{~cm})$ on the CAS-agar strain P. brenneri AS3 occurred after 16 hours of incubation at $37^{\circ} \mathrm{C}$. The maximum illumination zones $(2.0 \mathrm{~cm})$ were observed on the third day of incubation. As a positive control for the products used siderophore strain of Salmonella typhimurium (Figure 2). 


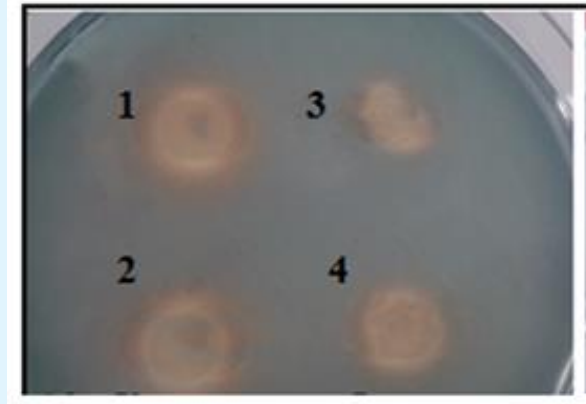

C: S. typhimurium. E: P. brenneri AS3 16 hours.

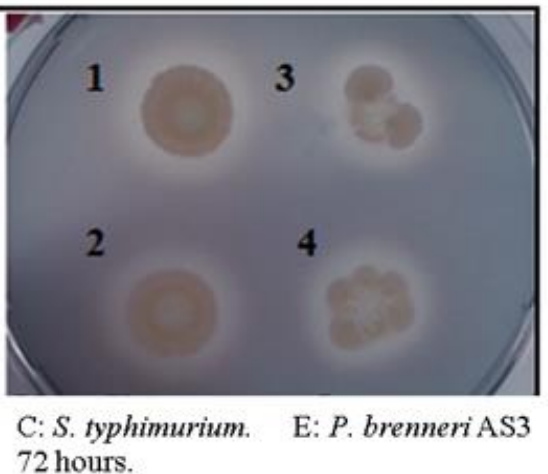

72 hours.

Figure 2: Siderophore production after 16 hours and after 72 hours. In two replicates, the control (C) was S. typhimurium $(1,2)$ and the experiment (E) was P. brenneri AS3 $(3,4)$.

The blue color of the medium is due to the formation of a complex of dye with iron ( $\mathrm{Fe} 3+$ ). The studied bacteria release redox-active substances (siderophores) into the environment, due to which the complex of dye and iron decays, since siderophores restore $\mathrm{Fe} 3+$ to $\mathrm{Fe} 2+$, and we observe a change in the color of the medium. Catechol type siderophores (Figure 8) are cyclic trilactone N-2,3dihydroxybenzoyl-L-serine (DHB-Ser) and its derivatives. The producers of this type of siderophores are some enterobacteria and bacilli, in contrast to the siderophores of the hydroxamate type, which are mainly produced by representatives of microscopic fungi.
The presence of siderophore of the catechol row was determined by the Arnou method, based on the formation of a complex of a metal with the hydroxyl group of siderophores. Catechol type siderophores at a concentration of $26.78 \mu \mathrm{M}$ (Figure 3) were detected for 5 $\mathrm{h}$ of cultivation of P. brenneri AS3 strain in M9 liquid medium. The maximum siderophore production $(82.05$ $\mu \mathrm{M})$ occurred at 28 hours of cultivation, whereas in the control strain Salmonella typhimurium, the maximum siderophore production $(50 \mu \mathrm{M})$ occurred at 24 hours of cultivation. At the time of maximum siderophore accumulation, the OD590 cell density was 0.739 , and the biomass was $6.25 \mathrm{~g} / \mathrm{l}(0.0070 \mathrm{~g}$ with $20 \mathrm{ml}$ of medium $)$ (Figure 3).

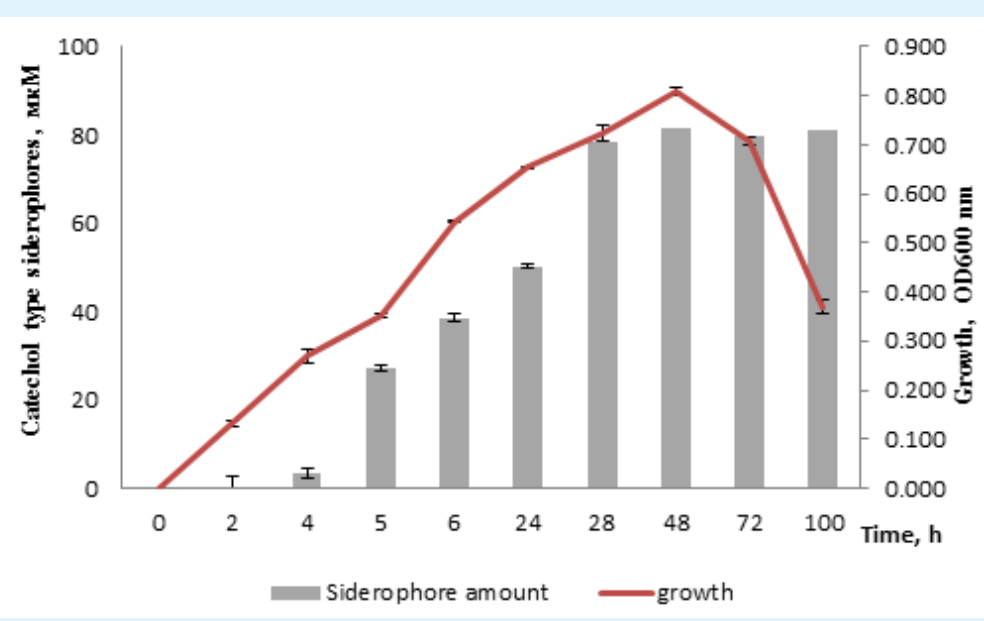

Figure 3: The dynamics of siderophore biosynthesis and strain growth. The gray columns indicate the formation of a siderophore of the catechol type by the strain; the red columns show the growth dynamics of the strain. 


\section{Open Access Journal of Microbiology \& Biotechnology}

Based on a study showing the high production of siderophore during short cultivation, P. brenneri AS3 strain can be recommended as the basis for creating innovative microbial agrobiotechnologies to solve problems associated with iron deficiency. Based on the study, indicating a high siderophore production over a short period of time, P. brenneri AS3 strain can be recommended as the basis for creating innovative microbial agrobiotechnologies to solve problems associated with plant diseases caused by phytopathogenic microorganisms and iron deficiency. Thus, the strain P. brenneri AS3 has multiple positive effects that can affect the growth and vital activity of plants.

The biocontrol function of the P. brenneri AS3 strain with respect to the pathogenic microflora of plant roots is, on the one hand, due to the stimulating effect on the plant, improving its vital status (increasing the intake of iron microelement), on the other hand, by isolating fungicidal substances and displacing phytopathogenic bacteria and fungi from the rhizosphere as a result of competitive suppression of their growth.

\section{Acknowledgment}

The reported study was funded by RFBR, project number 19-38-90208.

\section{References}

1. Wu H, Li Y, Ma Q, Li Q, Jia Z, et al. (2018) Metabolic engineering of Escherichia coli for high-yield uridine production. Metab Eng 49: 248-256.

2. Saghafi D, Delangiz N, Lajayer BA, Ghorbanpour M (2019) An overview on improvement of crop productivity in saline soils by halotolerant and halophilic PGPRs. 3Biotech 9(7): 261
3. Etesami H, Beattie GA (2018) Mining Halophytes for Plant Growth-Promoting Halotolerant Bacteria to Enhance the Salinity Tolerance of Non-halophytic Crops. Front Microbiol 9: 148.

4. Ferreira C, Soares H, Soares EV (2019) Promising bacterial genera for agricultural practices: An insight on plant growth-promoting properties and microbial safety aspects. Sci Total Environ 682: 779-799.

5. Payne SM (1994) Detection Isolation and Characterization of Siderophores. Methods enzymol 235: 329-344.

6. Evans GA (1989) Molecular Cloning: A Laboratory Manual. In: Sambrook J, Fritsch EF, Maniatis T (Eds.), Current protocols in molecular biology, John Wiley \& Sons, $2^{\text {nd }}$ (Edn.), Cold Spring Harbor Laboratory Press, New York: Cold Spring Harbor 61(1): 17-18.

7. Benjamin WH JR, Turnbough CL JR, Posey BS, Briles DE (1985) The Ability of Salmonella typhimurium to Produce the Siderophore Enterobactin Is Not a Virulence Factor in Mouse Typhoid. Infect immun 50(2): 392-397.

8. Nagarajkumar M, Bhaskaran R, Velazhahan R (2004) Involvement of secondary metabolites and extracellular lytic enzymes produced by Pseudomonas fluorescens in inhibition of Rhizoctonia solani, the rice sheath blight pathogen. Microbiol Res 159(1): 73-81.

9. Escobin-Mopera L, Ohtani M, Sekiguchi S, Sone T, Abe A, et al. (2012) Purification and characterization of phytase from Klebsiella pneumonia 9-3B. J Biosci Bioeng 113(5): 562-567. 